\title{
PERAN MOTIVASI DALAM MEMENGARUHI QUALITY OF WORK LIFE PADA KINERJA KARYAWAN
}

\author{
Neviyani, Roro Aditya Novi W \\ Pendidikan Ekonomi, FPIPS, IKIP PGRI Jember, Indonesia \\ nevi.phylo@gmail.com, dhee251110@gmail.com
}

\begin{abstract}
Abstrak: Peran Motivasi Dalam Memengaruhi Quality Of Work Life Pada Kinerja Karyawan. Tujuan penelitian: (1) Dampak Quality of Work Life pada Motivasi kerja karyawan; (2). Bagaimana dampak Motivasi kerja pada Kinerja karyawan? (3).Dampak Quality of Work Life pada Kinerja pada karyawan? (4).Bagaimana dampak Quality of Work Life dan Motivasi kerja pada Kinerja pada karyawan?. Populasi penelitian berjumlah 58 orang karyawan DIPO Lokomotif PT. KA (Persero) DAOP IX Jember yaitu masinis dan asisten masinis, Penelitian menggunakan Skala Likert dan Path Analysis Data. Hasil analisanya adalah (1). ada dampak yang sig. antara Quality of Work Life pada motivasi kerja, (2). terdapat dampak yang sig. antara motivasi kerja pada kinerja, (3). terdapat dampak yang sig. antara Quality of Work Life terhadap kinerja, (4). terdapat hubungan linier antara Quality of Work Life (X) serta motivasi kerja (Z) pada kinerja (Y).
\end{abstract}

Kata kunci : Quality of Work Life, motivasi, kinerja

\begin{abstract}
The Role Of Motivation In Affecting The Quality Of Work Life In Employee Performance. Research objectives: (1) Impact of Quality of Work Life on employee work motivation; (2). What is the impact of work motivation on employee performance? (3). Impact of Quality of Work Life on Performance on employees? (4). How will the impact of Quality of Work Life and Work Motivation on Performance on employees? The research population was 58 employees of PT. Locomotive DIPO. KA (Persero) DAOP IX Jember are machinists and machinist assistants. The research uses Likert Scale and Path Analysis Data. The results of the analysis are (1). there is an impact that sig. between Quality of Work Life on work motivation, (2). there is a significant impact. between work motivation on performance, (3). there is a significant impact. between Quality of Work Life on performance, (4). there is a linear relationship between Quality of Work Life $(X)$ and work motivation $(Z)$ on performance $(Y)$.
\end{abstract}

Keyword: Quality of Work Life, motivation, performance

\section{PENDAHULUAN}

Untuk membangun dan mengembangkan daya saing yang berkelanjutan, perusahaan harus mampu bertahan, di mana harus mampu melihat peluang terutama human capital yang terbangun dari kompetensi dan komitmen di dalam organisasi, untuk menciptakan nilai keunggulan pada perusahaan kini mulai bergeser dari pengelolaan asset berwujud ke pengelolaan strategi berbasispengetahuan yang menampilkan asset tidak berwujud. Serangkaian studi akhir-akhir ini menemukan korelasi strategi manajemen SDM dengan hasil kinerja karyawan, quality of work Life adalah salah satu faktor yang dapat mempengaruhi kinerja karyawan di dalam suatu perusahaan. Quality of work life meliputi delapan variabel yaitu: kompensasi, perasaan dalam satu kelompok, penggunaan seluruh kapasitas manusia, jaminan yang berkesinambungan, kondisi kerja, hak-hak karyawan, ruang kerja keseluruhan dan relevansi sosial (Jati, 2013). 
Quality of Work Life adalah dimana kemampuan perusahaan untuk memberikan kepuasan kebutuhan pribadi yang berasal dari pengalaman dari berbagai pekerjaan di dalam suatu perusahaan (Jannatin \& Hadi, 2012). Sehingga dapat di simpulkan bahwa Perbaikan terhadap quality of work life menekankan pada pendekatan positif terhadap problem-problem manusiawi dimana manajemen harus berupaya agar keseluruhan upaya yang dapat dan harus dilakukan yang keterlibatan anggota dalam mencapai tujuan organisasinya, karena quality of work life yang baik akan meningkatkan motivasi karyawan untuk meningkatkan performa kerjanya. Motivasi dapat dibedakan berdasarkan jenis-jenisnya. Ada jenis motivasi yang terjadi karena keinginan seseorang yang inginmendapatkan sesuatu. Jenis motivasi lain yaitu motivasi yang yangterjadi karena seseorang tersebut ingin mengejar target yang telah ditentukan agar berhasil sesuai dengan apa yang diharapkan.

Motivasi kerja adalah kemauan untuk berusaha yang di kondisikan oleh kemampuan individual untuk memenuhi beberapa kebutuahan yang dilakukan, untuk mencapai tujuan perusahaan atau organisasi. Pada sisi lainnya untuk mengetahui hasil atau ouput karyawan diperlukan tingkat pengukuran dimana para tenaga kerja dapat mencapai ketentuan-ketentuan tertentu di setiap instansi kerja (Sardiman, 2014).

Kinerja adalah pencapaian karyawan dalam melakukan tugasnya sesuai dengan tanggung jawab yang diberikan baik secara kualitas dan kuantitas. Menurut Simanjutak (2005),'Kinerja adalah tingkatan pencapaian hasil atas pelaksanaan tugas tertentu. Simanjuntak juga mengartikan kinerja individu sebagai tingkat pencapaian atau hasil kerja seseorang dari sasaran yang harus dicapai atau tugas yang harus dilaksanakan dalam kurun waktu tertentu”. Foster dan Seeker (2001) menyatakan bahwa, "Kinerja adalah hasil yang dicapai seseorang menurut ukuran yang berlaku untuk pekerjaan yang bersangkutan". Oleh karena itu dapat disimpulkan bahwa kinerja adalah kemampuan mencapai target atau sasaran sesuai dengan ketentuan yang telah disepakati terlebih dahulu.

Seiring perkembangan jaman, saat ini karyawan cenderung lebih memperhatikan kualitas hidup (quality of life) dibanding tahun-tahun sebelumnya, sehingga konsekuensinya isu-isu mengenai kualitas hidup pekerja (Quality of work life/QWL) menjadi persoalan penting bagi pengembangan sumber daya manusia. Data dalam penelitian Pratiwi dan Himan (2011) menyebutkan bahwa hHasil survei yang dilakukan oleh European Foundation for the Improvement of Living and Working Conditions (2007) menunjukkan upaya untuk memperoleh kehidupan kerja yang lebih baik serta pencapaian kesejahteraan (well-being)bagi karyawan menjadi masalah yang semakin penting untuk lebih diperhatikan. Selain masalah lingkungan fisik yang harus terus ditangani, masalah sosial dan psikologis juga mulai muncul. 
PT. Kereta Api Indonesia (Persero) DAOP IX Jember adalah perusahaan jasa yang bergerak di bidang transportasi darat. Sebagai penyedia sarana transportasi yang telah dikenal luas oleh masyarakat, PT. KAI (Persero) DAOP IX Jember harus memberikan pelayanan baik bagi masyarakat, dengan cara meningkatkan kinerja karyawan di DIPO Lokomotif yaitu masinis dan asisten masinis, karena mereka setiap hari berinteraksi langsung dengan masyarakat.

Dari data yang dimiliki oleh perusahaan 20\% kecelakaan kereta api di DAOP IX Jember diakibatkan kelalaian manusia (human error) dan 80\% diakibatkan karena kesalahan teknis (technical error). Human error bermacam-macam jenisnya, misal melanggar rambu-rambu, masinis tertidur saat berdinas atau karena pandangannya tertutup belasan penumpang gelap yang memenuhi lokomotif, kecepatan kereta api terlalu tinggi sehingga tergelincir. Sedangkan untuk kesalahan teknis seperti kereta anjlok akibat rel yang merenggang karena perawatan yang kurang intensif, sinyal yang tidak berfungsi yaitu lampu menyala hijau terus sehingga kereta dari arah depan sinyal melaju tanpa tahu bahwa di stasiun tersebut ada kereta yang "menunggu untuk ditabrak", banyak bantalan rel kereta api yang rusak karena termakan usia, tidak adanya pintu perlintasan dan kondisi cuaca di wilayah Jember yang akhir-akhir ini tidak menentu, sehingga sangat berpengaruh terhadap komposisi rel kereta api. Kinerja karyawan perusahaan harus ditingkatkan agar dapat melayani masyarakat secara optimal dan menjaga citra baik perusahaan dimata masyarakat diperlukan motivasi dalam meningkatkan quality of work life karyawan. Melalui dasar penjelasan di atas maka peneliti bertujuan ingin meneliti peran motivasi dalam memengaruhi quality of work life pada kinerja karyawan DIPO Lokomotif PT. Kereta Api (persero) DAOP IX Jember.

Setiyadi melakukan penelitian dengan judul Pengaruh Kualitas Kehidupan Kerja terhadap Kinerja Karyawan dengan Kepuasan Kerja sebagai Variabel Intervening (2016), menemukan adanya Penurunan tingkat kinerja karyawan penjualan pada tahun terakhir yaitu sebesar $1,1 \%$ pada kinerja istimewa dan target tingkat kemangkiran karyawan sebesar $1 \%$ tidak dapat tercapai menunjukkan kepuasan dan kualitas kehidupan karyawan dapat mempengaruhi penurunan kinerja karyawan. Permasalahan dalam penelitian ini adalah adakah pengaruh kualitas kehidupan kerja melalui kepuasan kerja terhadap kinerja karyawan. Hasil penelitian menunjukkan bahwa variabel kualitas kehidupan kerja berpengaruh positif terhadap kepuasan kerja; variabel kualitas kehidupan kerja berpengaruh positif terhadap kinerja karyawan; variabel kepuasan kerja berpengaruh positif terhadap kinerja karyawan; dan variabel kualitas kehidupan kerja berpengaruh secara tidak langsung melalui kepuasan kerja terhadap kinerja karyawan. Saran bagi perusahaan dalam meningkatkan kinerja karyawan agar memperhatikan aspek kualitas kehidupan kerja dan kepuasan kerja karyawan yang terbukti berpengaruh terhadap kinerja karyawan. Penelitian ke dua yang 
dilakukan oleh (Pratiwi, 2014) Saat ini, karyawan lebih sadar dengan masalah kualitas hidup daripada sebelumnya. Akibatnya, kualitas kehidupan kerja (QWL) juga menjadi masalah penting dalam pengelolaan sumber daya manusia dalam suatu organisasi. QWL yang lebih tinggi di tempat kerja membawa implication positif terhadap kinerja organisasi.

\section{METODE PENELITIAN}

Jenis penelitian yang digunakan adalah explanatory research. Populasi penelitian berjumlah 58 orang karyawan DIPO Lokomotif PT. KA (Persero) DAOP IX Jember yaitu masinis dan asisten masinis. Pengambilan data dilakukan kepada seluruh elemen populasi maka populasi sebagai sampel sehingga penelitianini menggunakan teknik sesnsus. Skala penelitian ini adalah Skala Likert. Path Analysis adalah yang digunakan untuk Analisa data dengan bantuan software SPSS.

\section{HASIL DAN PEMBAHASAN}

\section{a Hipotesis Pertama (Ha1)}

$\mathrm{H}_{1:}$ Quality of Work Life (X) berdampak sig. positif pada motivasi kerja (Z).

Tabel 1. Nilai koefisien analisis path dan pengujian hipotesis pertama

\begin{tabular}{|c|c|c|c|c|c|c|}
\hline \hline $\begin{array}{c}\text { Independen } \\
\text { Variabel }\end{array}$ & $\begin{array}{c}\text { Dependen } \\
\text { Variabel }\end{array}$ & Koef.B & $\mathbf{t}_{\text {hitung }}$ & $\mathbf{R}^{\mathbf{2}}$ & $\boldsymbol{p}_{\text {value }}$ & Ket. \\
\hline $\mathrm{X}$ & $\mathrm{Z}$ & 0,511 & 4,449 & 0,261 & 0,000 & $\begin{array}{c}\text { Ho ditolak/ } \\
\text { signifikan }\end{array}$ \\
\hline \hline
\end{tabular}

Hasil analisis path menunjukkan bahwa nilai koefisien jalur secara langsung (beta standardize) sebesar 0,511 dan sig. 0,000, karena pvalue $<\alpha$ atau 0,000 < 0,50 maka Ho ditolak. Pengujian signifikansi diperoleh $t_{\text {hitung }}$ adalah 4,449 statistik tabel satu sisi diperoleh angka 1,645. Maka Ho ditolak karena $t_{\text {hitung }}>t_{\text {tabel }}(4,449>1,645)$ atau hipotesis pertama $\left(\mathrm{Ha}_{1}\right)$ diterima, maka terdapat dampak yang sig. antara quality of work life pada motivasi kerja.

Analisa menunjukkan data bahwa berbagai komponen quality of work life (x) diantaranya kompensasi, perasaan dalam satu kelompok, penggunaan seluruh kemampuan manusia, kesempatan untuk kemajuan dan jaminan yang sinambung, kondisi kerja, hak-hak karyawan, fasilitas kerja seperti ruang kerja keseluruhan dan kesesuaian sosial sangat menentukan terbentuknya motivasi kerja (Z) yang tinggi dari karyawan. 


\section{b Hipotesis Kedua (Ha2)}

$\mathrm{Ha}_{2}$ Motivasi kerja (Z) berdampak positif sig. pada kinerja (Y).

Tabel 2. Nilai Koefisien Analisis Path Dan Pengujian Hipotesis Kedua

\begin{tabular}{|c|c|c|c|c|c|c|}
\hline \hline $\begin{array}{c}\text { Independen } \\
\text { Variabel }\end{array}$ & $\begin{array}{c}\text { Dependen } \\
\text { Variabel }\end{array}$ & Koef.B & $\mathbf{t}_{\text {hitung }}$ & $\mathbf{R}^{\mathbf{2}}$ & $\boldsymbol{p}_{\text {value }}$ & Ket. \\
\hline $\mathrm{Z}$ & $\mathrm{Y}$ & 0,340 & 2,657 & 0,335 & 0,010 & $\begin{array}{c}\text { Ho ditolak/ } \\
\text { signifikan }\end{array}$ \\
\hline \hline
\end{tabular}

Hasil analisis path menunjukkan koefisien jalur secara langsung (beta standardize) sebesar 0,340 dan $\mathrm{p}_{\text {value }}$ nya 0,010 , karena pvalue $<\alpha$ atau $0,010<0,50$ maka Ho ditolak. Hasil thitung adalah 2,675, diperoleh angka 1,645. Maka Ho ditolak karena $t_{\text {hitung }}>t_{\text {tabel }}(2,675>1,645)$ atau hipotesis kedua ( $\mathrm{Ha}_{2}$ ) diterima, dengan kata lain terdapat dampak yang sig. antara motivasi kerja terhadap kinerja.

Dari analisa menunjukkan data bahwa motivasi kerja $(\mathrm{Z})$ sangat menentukan terbentuknya kinerja (Y) yang tinggi dari karyawan.

\section{c Hipotesis Ketiga (Ha3)}

Ha3: Quality of work life (X) tidak mempunyai dampak yang positif sig. terhadap kinerja (Y).

Tabel 3. Nilai Koefisien Analisis Path Dan Pengujian Hipotesis Ketiga

\begin{tabular}{|c|c|c|c|c|c|c|}
\hline \hline $\begin{array}{c}\text { Independen } \\
\text { Variabel }\end{array}$ & $\begin{array}{c}\text { Dependen } \\
\text { Variabel }\end{array}$ & Koef.B & thitung & $\mathbf{R}^{\mathbf{2}}$ & $\boldsymbol{p}_{\text {value }}$ & Ket. \\
\hline $\mathrm{X}$ & $\mathrm{Y}$ & 0,326 & 2,552 & 0,335 & 0,014 & Ho ditolak/ signifikan \\
\hline \hline
\end{tabular}

Hasil analisis path pada tingkat kepercayaan 5\% diperoleh koefisien jalur secara langsung (beta standardize) sebesar 0,326 dengan p-valuenya 0,014, karena pvalue $<\alpha$ atau 0,014 $<0,50$ maka Ho ditolak. hasil $t_{\text {hitung }}$ adalah 2,552 statistik tabel satu sisi diperoleh angka 1,645. disimpulkan bahwa Ho ditolak karena $t_{\text {hitung }}>t_{\text {tabel }}(2,552>1,645)$ atau hipotesis kedua $\left(\mathrm{Ha}_{3}\right)$ diterima atau terbukti, maka berdampak sig. antara quality of work life pada kinerja.

Analisa menunjukkan data bahwa quality of work life $(\mathrm{X})$ sangat menentukan terbentuknya kinerja (Y) yang tinggi dari karyawan didukung oleh data empiris berupa penelitian yang dilakukan oleh Pratiwi. Hasil analisanya menyatakan variable quality of work life (QWL) berpengaruh pada kinerja, dengan sumbangan efektif $22,1 \%$, meskipun dilakukan penelitian kembali pada obyek dan 
responden yang berbeda namun pada Hasil analisa terbukti bahwa quality of work life dapat berdampak pada kinerja karyawan.

\section{d Hipotesis Keempat (Ha4)}

Ha4: Quality of work life (X) dan motivasi kerja (Z) tidak mempunyai dampak yang sig. dan positif pada kinerja (Y).

Dari uji regresi dengan melihat hasil koefisien baku menunjukkan bahwa variable quality of work life $(\mathrm{X})$ berdampak sig. pada variabel motivasi kerja $(\mathrm{z})$ dengan nilai $\beta=0,511$. Sehingga hipotesis pertama (H1) diterima, variabel motivasi kerja (Z) berdampak sig. terhadap variabel kinerja (Y) dengan nilai $\beta=0,340$. Sehingga hipotesis kedua (H2) diterima. Sehingga dapat disimpulkan terdapat hubungan linier antara quality of work life (x) serta motivasi kerja (z) terhadap kinerja (Y). sehingga hipotesis keempat dinyatakan diterima. Hasil analisa menunjukkan data bahwa quality of work life (x) dan motivasi kerja (z) sangat menentukan terbentuknya kinerja (Y) yang tinggi dari karyawan.

Berdasarkan model hasil pengujian hipotesis dan analisis jalur yang telah diteliti, maka terbukti bahwa semua hipotesis yang diajukan diterima. Artinya semua jalur mempunyai dampak langsung maupun tidak langsung secara sig. antara independen variable dengan dependen variable, sehingga model utama yang telah diajukan sebelumnya dapat ditetapkan sebagai model akhir analisis jalur.

Dari analisis hipotesis serta analisis path memperlihatkan hipotesis yang teliti diterima semua, yang artinya bahwa semua jalur mempunyai dampak baik langsung maupun tidak tidak langsung secara signifikan antara variabel independen dan dependen. Hasil analisis path yang diperoleh memperlihatkan bahwa dampak langsung quality of work life pada kinerja dengan nilai sebesar 0,511. Dampak langsung motivasi kerja pada kinerja dengan nilai sebesar 0,340. dan dampak tidak langsung quality of work life pada kinerja pada motivasi kerja adalah di tunjukkan dengan angka 0,173 .

\section{KESIMPULAN}

Hasil analisa data tentang dampak quality of work life dan Motivasi Kerja pada kinerja, diperoleh kesimpulan bahwa :

1. Terdapat dampak langsung signifikan dan positif quality of work life pada motivasi kerja. Artinya bahwa quality of work life berdampak secara sig. pada motivasi kerja, jika quality of work life diberikan secara baik oleh perusahaan maka motivasi kerja semakin meningkat.

2. Terdapat dampak langsung positif sig. variable motivasi kerja pada kinerja, artinya bahwa motivasi kerja memiliki dampak sig. pada kinerja, jika motivasi kerja karyawan meningkat, maka kinerja karyawan juga semakin ikut meningkat. 
3. Terdapat dampak langsung signifikan dan positif quality of work life pada kinerja, artinya variable quality of work life mempunyai dampak secara sig. terhadap kinerja, dan jika quality of work life meningkat dapat di artikan maka kinerja karyawan akan meningkat.

4. Terdapat dampak tidak langsung positif signifikan quality of work life dan motivasi kerja pada kinerja karyawan. Dari analisa menunjukkan bahwa dampak langsung $\mathrm{X}$ terhadap $\mathrm{Z}$ dan $\mathrm{Y}$ lebih besar dari pada dampak tidak langsung $\mathrm{X}$ melalui $\mathrm{Z}$ pada $\mathrm{Y}$.

Berdasar hasil analisa, pembahasan dan kesimpulan, maka rekomendasi yang bisa disampaikan adalah :

1. Mengingat tugas yang diemban masinis dan asisten masinis sangat berat, hal ini semata-mata agar karyawan termotivasi untuk lebih meningkatkan kinerja yaitu dengan memberikan kompensasi berupa asuransi jiwa, yang nantinya juga berakibat pada capaian tujuan perusahaan dan kredibilitas perusahaan dimata masyarakat.

2. Untuk lebih meningkatkan motivasi karyawan agar meningkatkan kinerjanya, perusahaan juga diharapkan dapat memperhatikan masalah kenyamanan serta keamanan lingkungan kerja, karena yang resiko yang terlihat cukup besar adalah masalah keamanan lingkungan kerja. Seperti menambah fasilitas antara lain ruang istirahat yang bisa digunakan ketika mereka selesai dinas, selain itu karyawan juga harus lebih kompak dengan rekan sekerja dengan memberikan bantuan ketika yang lain butuh bantuan atau menghadapi masalah dilapangan, jika mereka sudah merasakan aman dan nyaman dengan lingkungan kerjanya maka mereka akan senantiasa meningkatkan kinerja dan loyalitasnya pada perusahaan tanpa merasa khawatir akan keselamatan mereka sebagai wujud timbal balik bagi perusahaan

3. Bagi para akademisi dan peneliti selanjutnya, diharapkan bisa memperlebar kajiannya di bidang analisis path sebagai dasar acuan guna mengembangkan wawasan serta mengembangkan konsep teori.

\section{DAFTAR PUSTAKA}

Foster, Bill,dan Karen R.Seeker. (2001). Pembinaan Untuk Meningkatkan Kinerja karyawan. Penerjemah : Ramlan. Jakarta: PPM

Jannatin, M. K., \& Hadi, C. (2012). Pengaruh Kualitas Kehidupan Kerja ( Quality of Work Life ) terhadap Produktivitas Karyawan Produksi. Jurnal Psikologi Industri Dan Organisasi, 1-4

Jati, A. N. (2013). Kualitas Kehidupan Kerja Dan Komitmen Organisasional: Hubungannya Dengan Organization Citizenship Behavior. Kiat BISNIS.

Setiyadi. Pengaruh Kualitas Kehidupan Kerja terhadap Kinerja Karyawan dengan Kepuasan Kerja 
sebagai Variabel Intervening. (2016). Management Analysis Journal. https://doi.org/10.15294/maj.v5i4.12306

Pratiwi, K. (2014). Kualitas Kehidupan Kerja Ditinjau Dari Kepuasan Kerja Dan Persepsi Terhadap Kinerja. Jurnal Psikologi Undip. https://doi.org/10.14710/jpu.13.1.42-49

Sardiman, A. (2014). Interaksi Dan Motivasi Belajar Mengajar. In Interaksi \& Motivasi Belajar Mengajar.

Simanjuntak. 2005. Manajemen Dan Evaluasi Kinerja. Jakarta: Fakultas Ekonomi Universitas Indonesia.

\section{UCAPAN TERIMA KASIH}

Penulis mengucapkan terima kasih kepada rekan-rekan dosen yang telah memberikan masukan sehingga penelitian ini dapat terselesaikan, dan terima kasih juga di sampaikan kepada pihak DIPO Loomotif PT. KA (Persero) DAOP IX Jember.

\section{PROFIL PENULIS}

Neviyani, penulis pertama sebagai Dosen Pendidikan Ekonomi, FP IPS IKIP PGRI Jember, dengan jabatan Fungsional Asisten Ahli dengan latar belakang pendidikan S1 Pendidikan Ekonomi dan S2 Prgram studi Manajemen. Roro Aditya Novi W, penulis kedua sebagai Dosen Pendidikan Ekonomi, FP IPS IKIP PGRI Jember, dengan jabatan Fungsional Asisten Ahli dengan latar belakang pendidikan S1 Manajemen dan S2 Prgram studi Manajemen 